\title{
COVID-19; CHALLENGES AND OPPORTUNITIES IN NEPAL
}

\author{
Rimal HS \\ Professor, Dr. Hem Sagar Rimal, Department of Paediatrics, Birat Medical College and Teaching Hospital \\ https://orcid.org/0000-0002-5060-2611
}

\begin{tabular}{|c|}
\hline Citation \\
Rimal HS Covid-19; Challenges and Opportunity in Nepal. BJHS 2020, 5(1)11:879-880
\end{tabular}

DOI: https://doi.org/10.3126/bjhs.v5i1.29578

Humans are ingrained to fear the unknown. We want to be in control. We hate realizing that there are threats which we don't know enough about. We hate having to dwell in the dark. We hate putting our hands into cracks and crevices reaching for threads to show us where to go. This year had been just that. Unknown.

As the world spirals into seemingly apocalyptic chaos, we feel helpless, as though there is nothing we can do. For most of us, this is the first time witnessing a pandemic of such a devastating nature encompassing the globe, affecting millions of people while claiming hundreds of thousands of lives. The rapid spread of COVID-19 has hit 213 nations and territories around the world and taken over the world quite literally. COVID-19 was declared a global pandemic on the $12^{\text {th }}$ March 2020. In Nepal, the index case was reported on $24^{\text {th }}$ January 2020. As of the time of writing this editorial (26 June 2020), we have 11,162 confirmed cases and 27 deaths. This new disease was everything that we feared. It was new, rapidly changing, and very hard to control. There was limited information regarding the causative agent, pathogenesis of the disease, clinical presentation, investigation and management approach. The approaches taken by governments across the world for the prevention of the spread of the disease include mandatory lockdown, social distancing, closure of schools, ban on unnecessary public gatherings, rapid testing, contact tracing, isolation of positive cases and provision of quarantine centers for those arriving from regions of high disease burden. Although all of this may all seem very dark and distressing (which is as evident hopefully by the delay in this very publication!), it has also created opportunities for people of all sectors.

The scientific community found itself in untested waters. The diagnosis and test utilization for this novel virus was up for debate. With no existing precedents to build upon, a global coalition of leading scientists had to come together to build a foundation from which the fight against the pandemic could rise. Questions like what tests are the most useful and the exact procedure of organizing and managing testing was decided upon and applied globally. Two major tests have come to the fore, an antibody test that detects prior infection and a RT - PCR test that confirms the diagnosis in the present. This holds true for our country and almost every other country across the world. The uniformity seen here is a testament to the unity of the global scientific community. It is unfair to talk of scientific unity without mention of the COVID - 19 vaccine effort. Chinese researchers were the first to sequence the viruses genome, and they promptly shared their findings with the rest of the world. Australian researchers replicated the virus in their laboratory and this technique was also made available to the public. Oxford researchers have shown promising signs of a vaccine and Dexamethasone has been shown to improve the prognosis in the sickest of the sick. This is the greatest collaboration the world has seen in the field of medicine since the eradication of Small Pox.

The pandemic has also shown that the use of technology and introduction of telemedicine system to provide support to patients and their families remotely by consultation with specialists through phone calls, videos is very useful. We have noticed increased cases of psychological issues, anxiety, depression, self harm, suicide and Post traumatic stress disorders among COVID-19 affected as well as infected population that are linked to uncertainty about the pandemic, social isolation, financial burden and loss of loved ones among many other reasons.

There is an opportunity for our policy makers and politicians to identify the gaps in mental health policies and develop a robust mental health system having referral and supporting system to reach out at the community level. The cultural practices, resilience of Nepali people and timely considered public health measures are hopefully helpful in mitigating risk and spread of disease.

Medical education was not an exception in being affected by this pandemic. All the medical institutions in Nepal very quickly 
embraced the concept of online education and gave continuity to teaching learning activities that prevented undue delay in the educational endeavors of medical students. Faculties were very flexible to adopt newer methods of teaching through the internet within a short span of time. This in itself could bring a paradigm shift in medical education which may continue in the foreseeable future.

This pandemic has alarmed the government, policy makers and public health experts to findgaps in the national and regional health system and bridge it with proper planning to combat similar outbreaks which may happen in future.There has been great strides forward in this regard in Nepal. The government has been working hard to control the disease, but there is still a lot to be done. There is still much to improve and many potholes to be filled. The road that COVID-19 has laid is a rough one, but it is a road nonetheless. It is up to all of us to decide how we want to pave it.

\section{REFERENCE}

1. World Health Organization Novel corona virus ( 2019-nCoV0- situation report-10-30 January 2020.https:// www.who.int/ docs/defaultsource/coronaviruse/situation-reports/20200130-sitrep-10ncov.pdf? sfvrsn=d0b 2e480_2.2020.

2. Sian Williams and Ioanna Tsiligianni et al . COVID -19 poses novel challenges for global primary care. npj Primary Care Respiratory Medicine (2020) 30:30; https://doi.org/10.1038/s41533-020-0187-x

3. Patel R, Fang FC. 2018. Diagnostic stewardship: opportunity for a laboratory-infectious diseases partnership. Clin Infect Dis 67:799 801. doi: 10.1093/cid/ciy077

4. http://documents.worldbank.org/curated/en/145161586536 712080/Purpose-and-Options-for-Testing-for-SARS-Cov2-the-COVID19-Virus-Considerations-for-World-Bank-Task-Teams-ManagingCOVID-19-Fast-Track-Facility Operations

5. A. Bastola, R. Sah, A.J. Rodriguez-Morales, B.K. Lal, R. Jha, H.C. Ojha, et al. The first 2019 novel coronavirus case in Nepal Lancet Infect Dis, 20 (2020), pp. 279-280. 